\title{
A phylogenomic approach to reconstruct interrelationships of main clupeocephalan lineages with a critical discussion of morphological apomorphies
}

\author{
Nicolas Straube ${ }^{1,2^{*}}$ (D), Chenhong Li ${ }^{3}$, Matthias Mertzen ${ }^{1,4}$, Hao Yuan ${ }^{3}$ and Timo Moritz ${ }^{1,4}$
}

\begin{abstract}
Background: Previous molecular studies on the phylogeny and classification of clupeocephalan fishes revealed numerous new taxonomic entities. For re-analysing these taxa, we perform target gene capturing and subsequent next generation sequencing of putative ortholog exons of major clupeocephalan lineages. Sequence information for the RNA bait design was derived from publicly available genomes of bony fishes. Newly acquired sequence data comprising $>800$ exon sequences was subsequently used for phylogenetic reconstructions.

Results: Our results support monophyletic Otomorpha comprising Alepocephaliformes. Within Ostariophysi, Gonorynchiformes are sister to a clade comprising Cypriniformes, Characiformes, Siluriformes and Gymnotiformes, where the interrelationships of Characiformes, Siluriformes and Gymnotiformes remain enigmatic. Euteleosts comprise four major clades: Lepidogalaxiiformes, Protacanthopterygii, Stomiatii, and Galaxiiformes plus Neoteleostei. The monotypic Lepidogalaxiiformes form the sister-group to all remaining euteleosts. Protacanthopterygii, comprising Argentini-, Esoci- and Salmoniformes, is sister to Stomiatii (Osmeriformes and Stomiatiformes) and Galaxiiformes plus Neoteleostei.

Conclusions: Several proposed monophyla defined by morphological apomorphies within the Clupeocephalan phylogeny are confirmed by the phylogenetic estimates presented herein. However, other morphologically described groups cannot be reconciled with molecular phylogenies. Thus, numerous morphological apomoprhies of supposed monophyla are called into question. The interpretation of suggested morphological synapomorphies of otomorph fishes is strongly affected by the inclusion of deep-sea inhabiting, and to that effect morphologically adapted Alepocephaliformes. Our revision of these potential synapomorphies, in the context that Alepocephaliformes are otomorph fishes, reveals that only a single character of the total nine characters proposed as synapomorphic for the group is clearly valid for all otomorphs. Three further characters remain possible apomorphies since their status remains unclear in the deep-sea adapted Alepocephaliformes showing developmental lag and lacking a swim bladder. Further, our analysis places Galaxiiformes as sister group to neoteleosts, which contradicts some previous molecular phylogenetic studies. This needs further investigation from a morphological perspective, as suggested synapomophies for several euteleostean lineages are challenged or still lacking. For the verification of results presented herein, a denser phylogenomic-level taxon sampling should be applied.
\end{abstract}

Keywords: Otomorph characters, Euteleostei, Alepocephaliformes, Synapomorphies, Target gene capture, Next generation sequencing, Evolmarkers

\footnotetext{
* Correspondence: straube@snsb.de

'Institut für Zoologie \& Evolutionsbiologie, Friedrich-Schiller-Universität Jena,

Erbertstraße 1, 07743 Jena, Germany

${ }^{2}$ Zoologische Staatssammlung München, Staatliche Naturwissenschaftliche

Sammlungen Bayerns, Münchhausenstraße 21, 81247 Munich, Germany

Full list of author information is available at the end of the article
}

(c) The Author(s). 2018 Open Access This article is distributed under the terms of the Creative Commons Attribution 4.0 International License (http://creativecommons.org/licenses/by/4.0/), which permits unrestricted use, distribution, and reproduction in any medium, provided you give appropriate credit to the original author(s) and the source, provide a link to the Creative Commons license, and indicate if changes were made. The Creative Commons Public Domain Dedication waiver (http://creativecommons.org/publicdomain/zero/1.0/) applies to the data made available in this article, unless otherwise stated. 


\section{Background}

With approximately 32,000 species, the teleost fishes comprise about half of the vertebrate species, with representatives in almost any aquatic environment from montane habitats to the deep-sea. With the progress in gene sequencing technologies, several phylogenetic hypotheses have been published for Teleostei in recent years advancing from single gene alignments to mitochondrial genomes and multi-locus approaches increasing in the taxonomic diversity analyzed. However, major discrepancies are evident between morphology and molecular phylogenetics [1-6] and between different DNA sequence based datasets. Further, several deep phylogenetic nodes remain enigmatic [2]. In the course of this paper, we are referring to the classification suggested in [2], if not indicated otherwise.

Phylogenetic analyses suggest that Teleostei comprises three main lineages: Osteoglossomorpha, Elopomorpha and Clupeocephala with the latter being the largest by far. The monophyly of the supercohort Clupeocephala is evidenced by both morphological and molecular data [1, 2, 5-7]. Wiley and Johnson [6] suggested Clupeocephala to contain two major lineages, the Otomorpha and Euteleostei (Fig. 1a). Otomorpha are suggested to comprise the Clupei (herrings and allies, also referred to as Clupeomorpha) and Ostariophysi. The diverse subcohort Ostariophysi includes the most species rich and predominantly fresh water inhabiting lineages, the Cypriniformes (carps) as well as the Siluriformes (catfishes). Further, the clade comprises Gonorynchiformes (milkfishes), Characiformes (characins and allies) and Gymnotiformes (neotropical knifefishes) (Fig. 1). With more than 10,000 described species, the Ostariophysi pose a noteworthy part of today's Clupeocephalan overall diversity. The situation gets complicated by results from molecular phylogenetic studies providing strong evidence that Alepocephaliformes are Otomorpha $[1,2,5,8-10]$ (Fig. 1b,c). Contrasting all other otomorph fishes, Alepocephaliformes represent a group of deep-sea fishes, which show extensive morphological adaptations to their habitat making a morphological comparison to other taxa within Otomorpha difficult. The first detailed morphological investigation on the systematic position of alepocephaliformes [11] placed them as sistergroup to the Argentinoidei (marine smelts and allies), which was adopted in the classification of [6], placing the Alepocephaloidei in the order Argentiniformes among euteleost fishes. Therefore, molecular phylogenetic analyses challenge proposed morphological synapomorphies on at least five phylogenetic levels rendering higher-level taxa Euteleostei, Otomorpha, Protacanthopterygii, Argentinoidei and Alepocephalodei either poly- or paraphyletic. a) Morphological classification [6]

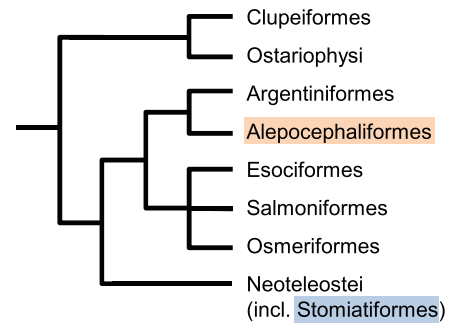

d) 20 nDNA loci \& 1 mtDNA locus [1]

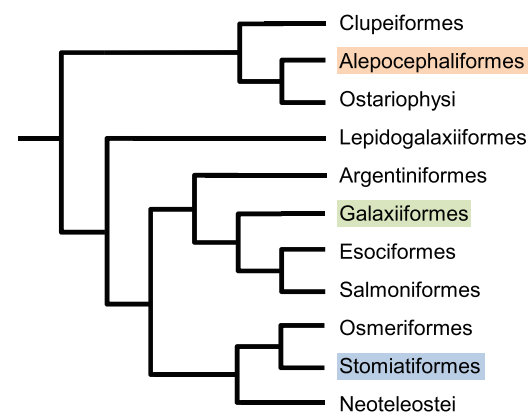

b) Mitochondrial genome [3]

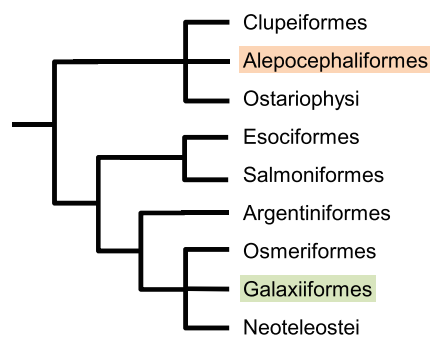

e) 28 nuclear, 13 mtDNA loci \& 274 morphological characters [30]

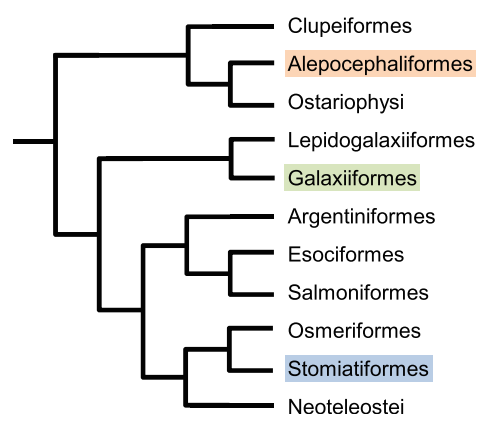

c) Nine nDNA loci [5]

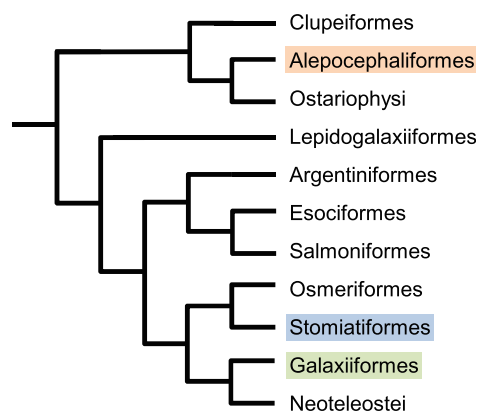

f) 20 nDNA loci, 1 mtDNA locus \& partially phylogenomic data [2]

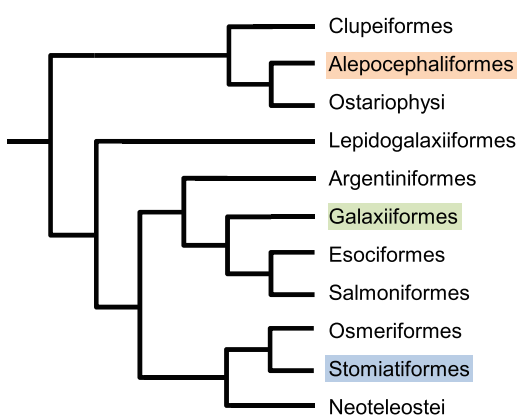

Fig. 1 Summary of previous phylogenetic estimates and classifications of Clupeocephalan fishes. Colours indicate taxa with variable phylogenetic positions 
A sister-group relation of clupeomorphs and ostariophyseans was first proposed by Lecointre and Nelson [12]. The respective taxonomic unit, the Otomorpha [6], also named Otocephala [13] or Ostarioclupeomorpha [14], was soon established, but morphological evidence supporting the monophyly of the group remained scarce $[6,12,14,15]$. The following nine characters have been discussed as possible apomorphies for otomorphs: (1) ossification of autopalatine early in ontogeny- within the palatoquadrate cartilage three bones autogenously ossify. The ancestral teleost condition is an autopalatine, which forms clearly later than metapterygoid and quadrate [16]. Arratia and Schultze [16] found that the autopalatine in Denticeps, Dorosoma and Chanos ossifies at the same ontogenetic stage. In salmonids, it ossifies slightly later compared to the otomorph palatoquadrate ossification sequence and the authors suggested an early ontogeny of an autopalatine as synapomorphy for Clupeocephalans. In more primitive taxa such as Osteoglossomorpha or Elopomorpha, the ossification of the autopalatine takes place significantly later. Subsequent studies proposed that this character was not apomorphic for clupeocephalans but otomorphs [12-15]. Later, Arratia [7, 17] revised this statement and re-defined the character as apomorphic for the Clupeocephalans again. (2) Fusion of medial extrascapulars with parietals- the absence of a separate median sensory canal bone in the supratemporal commisure, resulting in a canal in the parietal and supraoccipital bones, was first reported from clupeomorphs and regarded as apomorphic for this group [18]. Such a condition is usually interpreted as a fusion of the medial extrascapular to the parietal [12]. A respective fusion without inclusion of the supraoccipital was also reported from some species of Gonorynchiformes [19], Cypriniformes, and Characiformes [20, 21]. This led to the conclusion that the character is of apomorphic state in Otomorpha $[6,12,15]$.

(3) Ossified epicentrals- ossified epicentrals are documented already in the Elopomorpha [22], which excludes this character as an apomorphy for Otomorpha. (4) Connection of swim bladder and ear - the otophysic connection, i.e. the connection between swim bladder and inner ear, fundamentally differs in Clupeomorpha and Otophysi [23-25]. The evolutionary sequence between these two states is unknown. Furthermore, gonorynchiform species do not show an otophysic connection [23, 25], but only show adaptations, which can be interpreted as ancestral conditions of an otophysic connection of the Ostariophysi-type: the division of the swim bladder into an anterior and posterior chambers and an enlarged first rib. This leads to the conclusion that this character cannot be regarded as an apomorphy for otomorphs. Alepocephalids lack a swim bladder and and thus cannot contribute to evaluate this character. (5) Anterior chamber of swim bladder partly or completely covered by silvery peritoneal tunic- a completely or partially silvery peritoneal cover of the anterior chamber of the swim bladder [23] was discussed as possibly apomorphic for Ostariophysi [24]. Clupeomorph swim bladders do not show an anterior-posterior division as in Ostatariophysi, however, within their single chambered swim bladder, the anterior part is also covered with a silvery peritoneal tunic. Therefore, this character is regarded as apomorphy for otomorphs [26]. (6) Heamal spines anterior to second preural centrum fused to centra early in ontogeny- the character "hemal spine of preural-centrum 3 (PU3) and anterior vertebrae fused with their respective centra" [26] usually is supplemented with the information that the character is already developed "from a young juvenile stage on" [6, 14, 24]. Fink and Fink [24] found that also clupeomorphs have all hemal spines fused to their centra and interpreted this condition as hint to a "relationship between Clupeomorpha and Ostariophysi". Later, however, the Fink and Fink [24] listed the same character as an ostariophysean apomorphy disregarding the clupeomorph condition [24]. The interpretation of this character in the light of recent phylogenetic hypothesis is difficult as the deep-sea dwelling alepocephalids show reductions and developmental lag in ossifications. (7) Presence of a pleurostyl- a pleurostyl is found in clupeoids and Ostariophysi $[27,28]$. Most clupeiforms and Ostariophysi have a pleurostyl. The sister-taxon of all clupeiforms, Denticeps, as well as fossil stem-group representatives of Ostariophysi, however, do not show this character. In herring-like fishes, it is a fusion of the first uroneural to the (first) preural centrum $[27,28]$. Respective fusions in the caudal skeleton of Ostariophysi are more comprehensive and include additionally both ural centra and the hypural 2 [24]. (8) Lack of cartilaginous connection between the bases of hypurals 1 and 2- the lack of a cartilaginous connection between bases of the hypurals 1 and 2 at any ontogenetic stage was proposed as apomorphy for otomorphs $[6,14,15]$. (9) Fusion of hypural 2 with compound centrum. A fusion of hypural 2 with the first ural centrum is present in Otophysi and Clupeomorpha [6, 24, 27, 28]. Such a fusion is, on the other hand, absent from all gonorynchiforms except Gonorynchus in which, however, caudal element fusions are extensive [25].

In summary, morphological evidence supporting the taxon otomorpha is scarce. Further, several of the proposed apomorphic characters are doubtful and have already been critically discussed $[6,7,12,13]$.

With advances in sequencing technology, phylogenetic analyses shifted from analysing morphological matrices to sequence alignments with growing number of genes and taxa included in the analyses. Based on molecular 
phylogenetic results, Betancur-R. et al. [2] define the Euteleostei (referred to as Eutleosteomorpha in [2]) to comprise several newly defined clades in their new classification of bony fishes, for example the Lepidogalaxiiformes, a taxonomic unit comprising a single extant species only, the West-Australian salamander fish Lepidogalaxias salamandroides. Molecular phylogenetic analyses suggest this species to form the sister taxon to all other euteleost lineages [29]. Besides its unexpected phylogenetic position suggested by molecular data, it also displays numerous noteworthy morphological characters indicating strong specialization and, contrasting molecular phylogenetics, a close phylogenetic relationship with Galaxiiformes [30]. Following Betancur-R. et al. $[1,2]$, the sister clade of Lepidogalaxiiformes is unnamed including three major clades: the Protacanthopterygii as sister to a clade comprising Stomiatii and Neoteleostei. The Protacanthopterygii sensu Betancur-R. et al. [1, 2] comprise Argentiniformes, Galaxiiformes, Salmoniformes (salmons) and Esociformes (pikes and mudminnows) (Fig 1c). It should be noted that, contrasting [1, 2], Near et al. [5] found the Galaxiiformes to form a sister group relationship with neoteleosts, i.e. the order was not clustering along with the Protacanthopterygii sensu Betancur-R. et al. [1, 2] (Fig. 1d, f). From a morphological perspective, another noteworthy result from DNA sequence data is the sister group relationship of Osmeriformes (smelts) with Stomiatiformes (dragonfish) forming the Stomiatii (Fig. 1c, d e, f). Morphological studies considered dragonfishes hitherto as neoteleost fishes sharing proposed neoteleost synapomorphies, especially in branchial arch musculature and tooth attachment type [6]. Wiley and Johnson [6] commented that homology of these characters has not been evaluated from an ontogenetic perspective in Stomiatiformes and such information is still lacking. Hence, the classification in Betancur-R. et al. [1] challenged the morphological monophyly of neoteleosts and calls the suggested synapomorphic characters into question. Results presented in Betancur-R. et al. [1, 2] reproduce neoteleost fishes as sister to the Stomiatii/ Protancanthopterygii clade. In their phylogenetic tree reconstruction, however, this split lacks high node support, confirming the split between Stomiatii and Neoteleosts. A similar situation is apparent in the sister group relationship of Protacanthopterygii and the Stomiatii/ neoteleost clade. With updating the classification of bony fishes [2], Protacanthopterygii are sister to a clade now comprising Stomiatii and Neoteleostei. Among neoteleosts, Ateleopodiformes (jellynose fishes) are sister to all further higher-level taxa referred to as Eurypterygia (Cyclosquamata, Ctenosquamata, Acantomoprhata, Euacantomorphacea, and Percomorphata).

In a recent and extensive study, Mirande [31] combines both morphological and molecular data to re-infer the major phylogenetic relationships within Acanthopterygii. The parsimony-based phylogenetic estimates [31] are only partially in accordance with studies analyzing solely molecular data, demonstrating the contrarious phylogenetic signals by morphological and molecular data. The final hypothesis of Mirande [31] recovers the Clupeocephala with high Bremer support, while the Otomorpha, including the Alepocephaliformes as sister to the remaining otomorph taxa, appear only weakly supported. The well-supported euteleosts show two major clades, one comprising Lepidogalaxiiformes and Galaxiiformes as sister groups to all remaining euteleost lineages. The monophyly of the Lepidogalaxiiform/ Galaxiiform clade is only weakly supported. A sister group relationship of Protacanthopterygii (sensu Betancur-R. et al. [1, 2]) and Stomiatii is not well supported, while the monophyly of neoteleosts appears underpinned based on Bremer support (Fig. 1e).

In summary, several taxonomic entities proposed in previous phylogenetic studies analyzing molecular data are not supported by presently available morphological data. In times of next generation sequencing, researchers started to conduct phylogenomic level approaches to resolve difficult phylogenetic questions such as otophysan interrelationships [32, 33].

Here, we apply a targeted gene capture approach using a set of curated RNA baits to attain a phylogenomic-level dataset of potential ortholog loci to test, if we can sequence a sufficient number of genes from non-model organisms to resolve deep phylogenetic nodes on ordinal level within the evolutionary oldest Clupeocephalan lineages. In this study, we test if (1) we can resolve the otomorph phylogeny and (2) discuss previously suggested morphological synapomorphies of Otomorpha in the light of our phylogenomic reconstruction. (3) New insights in to the phylogeny of deep phylogenetic nodes of Euteleostei are discussed with regard to previous phylogenetic reconstructions and morphological characters.

\section{Results}

Sequencing of 52 taxa resulted in an average number of 6.3 million paired-end reads per specimen. After adaptor and quality trimming of reads, per taxon reads were blasted [34] against bait sequences to create gene bins. Reads mapped to target loci were de-novo assembled resulting on average in 3400 contigs per specimen. After reciprocally blasting specimen contigs against the reference genome, which was used for bait design, 368 loci were identified as potential paralogs and excluded from further analysis steps. 13,681 loci were available for the cross-contamination check. The highest percentage of potential cross-contamination between pair of taxa among these loci was only $1.44 \%$, which meant there was no cross-contamination among our samples. (Additional file 1: Table S2). The latter were excluded 
from further analyses. The search for phylogenetically informative loci applying the Matrix Reduction Software MARE [35, 36] identified 838 most informative loci. Additional checks for orthology [37, 38] identified four further loci flagged as potential paralogs (Additional file 1: Table S3) and were exlcuded from subsequent analysis. Another five loci were excluded, which contained less than four taxa. These 829 most informative loci were phylogenetically analysed totaling 202,922 possible sites per specimen in the concatenated nucleotide alignment. RAxML found 117,046 distinct alignments patterns and a proportion of gaps and undetermined characters of $60.3 \%$. The alignments are available for download at the Dryad data repository [39]. See Fig. 2 and Additional file 1: Table S1 for a summary of target capture success.

\section{Phylogenetic analyses}

The results from Partitionfinder and PartitionfinderProtein [40-42] and best-fitting partitioning schemes for the maximum likelihood analyses of the concatenated datasets are available for download at the Dryad data repository [39]. ESS values derived from the Phylobayes [43] analyses are further listed in Additional file 1. Overall, results were indicating high quality runs, as the comparisons of bipartition frequencies is around 0.1 for both runs (Additional file 1).

Different phylogenetic estimates in this study are widely congruent with few exceptions, which will be subject of the discussion. Please refer to Fig. 3 and Table 1 for tracking the results listed below. After rooting all resulting trees with the two elopomorph taxa Elops senegalensis and Anguilla anguilla, Pantodon buchholzi, representing the Osteoglossomorpha, forms the sister group of the monophyletic and well-supported Clupeocephala. Clupeocephala are split in two major clades, Otomorpha, comprising Clupeiformes, Alepocephaliformes and Ostariophysi (Rutilus and Danio (Cypriniformes), Gonorynchus, Cromeria and Chanos (Gonorynchiformes), Gymnotus (Gymnotiformes), Alestes and Distichodus (Characiformes) and Schilbe (Siluriformes), and euteleosts including Lepidogalaxias (Lepidogalaxiiformes), Galaxias and Lovettia (Galaxiiformes), Esox, Dallia and Umbra (Esociformes), Bathylagus, Nansenia, Argentina and Opisthoproctus (Argentiniformes), Salmo and Coregonus (Salmoniformes), Stomiatii (Osmerus, Mallotus, Salanx and Plecoglossus representing Osmeriformes) and Borostomias, Astronesthes and Maurolicus representing the Stomiatiformes). Monophyletic Neoteleostei are part of the euteleosts and represented by several species of Aulopiformes, Ateleopodiformes and Trachypterus (Lampridiformes).

Within Otomorpha, we recovered three major clades, Clupeiformes, Alepocephaliformes, and Ostariophysi.
Clupeiformes are sister to a clade comprising Alepocephaliformes and Ostariophysi (Fig. 3). Alepocephaliformes as sister to Ostariophysi is well-supported by all analyses based on nucleotide alignments, whereas amnio acid based analyses result in Alepocephaliformes as sister to a clade comprising Clupeiformes and Ostariophysi (Table 1). Different types of phylogenetic analyses and datasets (i.e. concatenated amino acid versus concatenated DNA alignments and coalescent analyses) partially show weak node support for the phylogenetic placement of Alepocephaliformes as sister to Ostariophysi (Fig. 3, Table 1). The ASTRAL [44] species tree computed from maximum likelihood trees based on amino acid single loci alignments result in a topology where Alepocephaliformes are sister to a clade including Clupeiformes and Ostariophysi (Additional file 1: Figure S7). In several phylogenetic analyses Gonorynchus forms a distinct lineage as sister-group to all remaining Ostariophysi (Table 1; Additional file 1: Figures S6 \& S8). In all other analyses (Table 1), monophyletic Gonorynchiformes are clearly supported as the sister group of Otophysi (Table 1; Additional file 1: Figures S1-S5, S7).

All analyses recover Cypriniformes as sister to a clade comprising Characiformes, Gymnotus (Gymnotiformes) and Schilbe (Siluriformes) with high node support (Table 1), however, the relationships within the latter clade differ between analyses. While several analyses result in Gymnotus forming the sister lineage to a clade comprising Alestes, Distichodus and Schilbe (Table 1; Additional file 1: Figures S3, S4, S8), i.e. rendering Characiformes paraphyletic, only the concatenated amino acid dataset recovers interrelationships as suggested from morphology e.g. [24] and a comprehensive recent phylogenomic study [32] (Table 1, Additional file 1: Figures $\mathrm{S} 1-2$ ).

Regarding euteleost lineages, the phylogenetic analyses recover monospecific Lepidogalaxias as sister-group to all remaining euteleost groups (Table 1, Fig. 3, Additional file 1: Figures S1-8). The major euteleost clade comprises protacanthopterygians sensu [1, 2] excluding Galaxiiformes, i.e. Argentiniformes sister to a clade comprising Esociformes and Salmoniformes. This clade is sister to a clade including Stomiatii sensu Betancur-R. et al. [1, 2], Galaxiiformes and Neoteleostei. All analyses performed here support monophyletic Stomiatii comprising Stomiatiformes and Osmeriformes. Retropinna is sister to a clade comprising further osmeriforms representing the major families. The Stomiatii are the sister clade to Galaxiiformes and Neoteleostei. The Galaxiform samples (Galaxias and Lovettia) included in this study form the sister taxon to the neoteleost lineage in all analyses with high node support (Table 1) contradicting results presented in Betancur-R. et al. [1, 2].

The following splits are variable in different types of phylogenetic analyses. Protacanthopterygii (excluding 


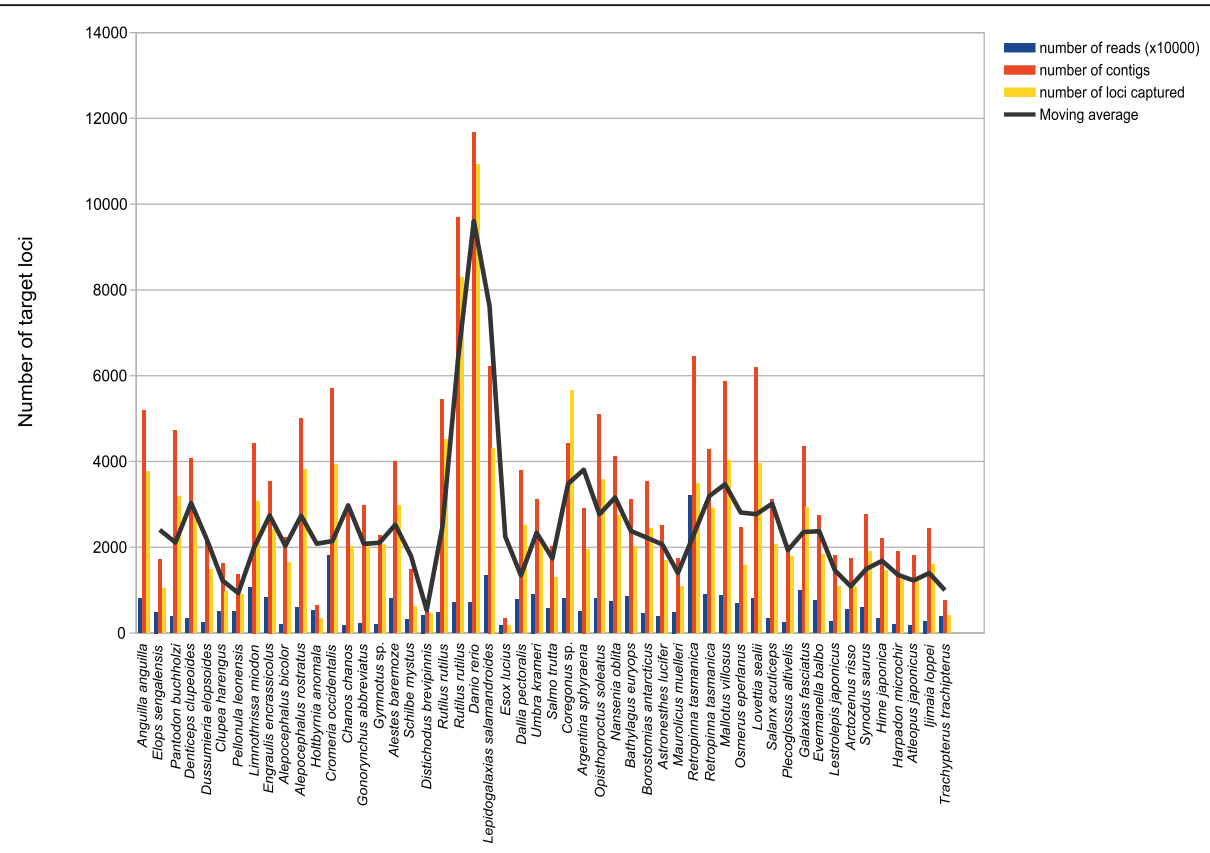

Fig. 2 Summary of target capture success. X-axis: target species; $y$-axis: number of target loci captured per specimen

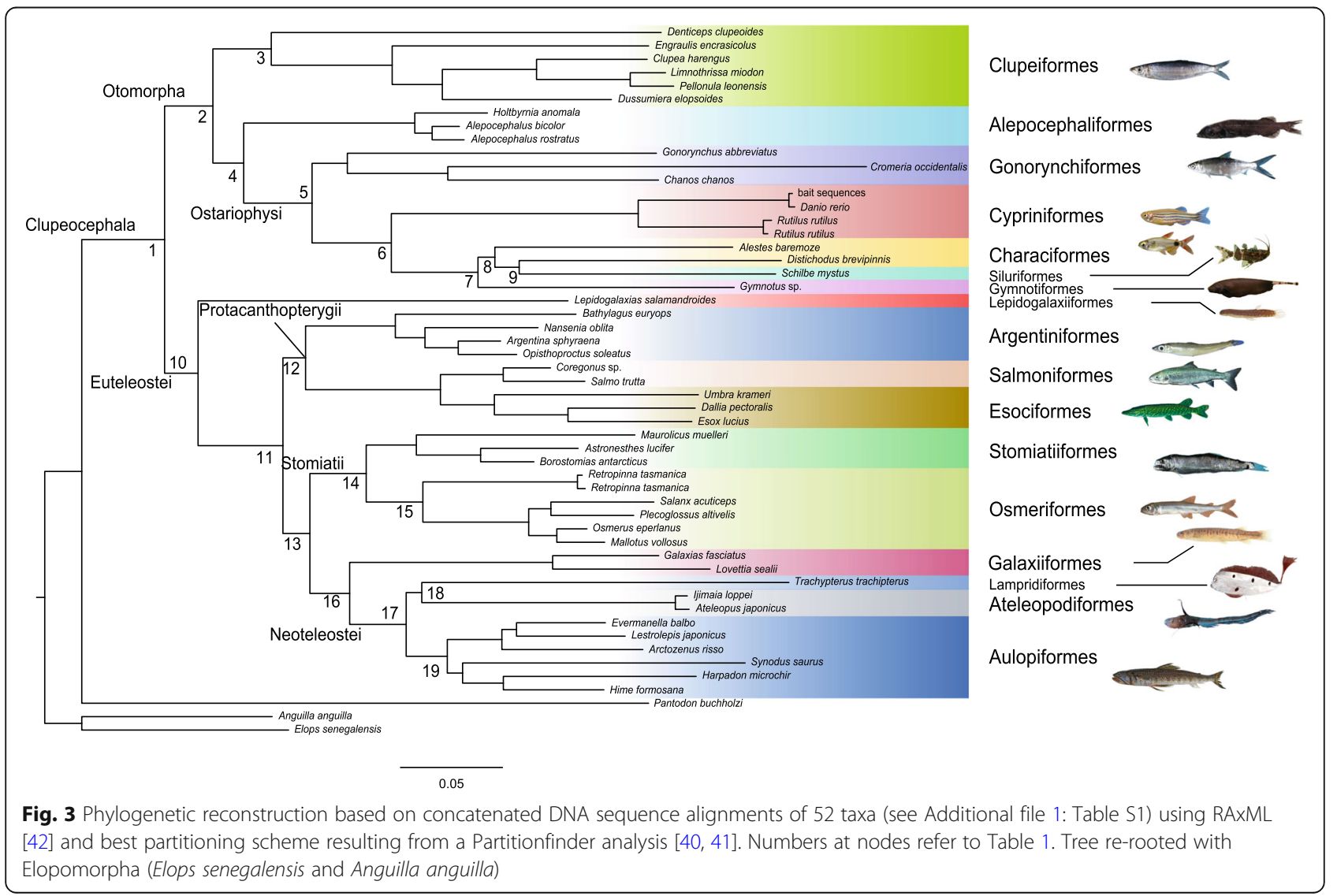


Straube et al. BMC Evolutionary Biology $\quad$ (2018) 18:158

Page 7 of 17

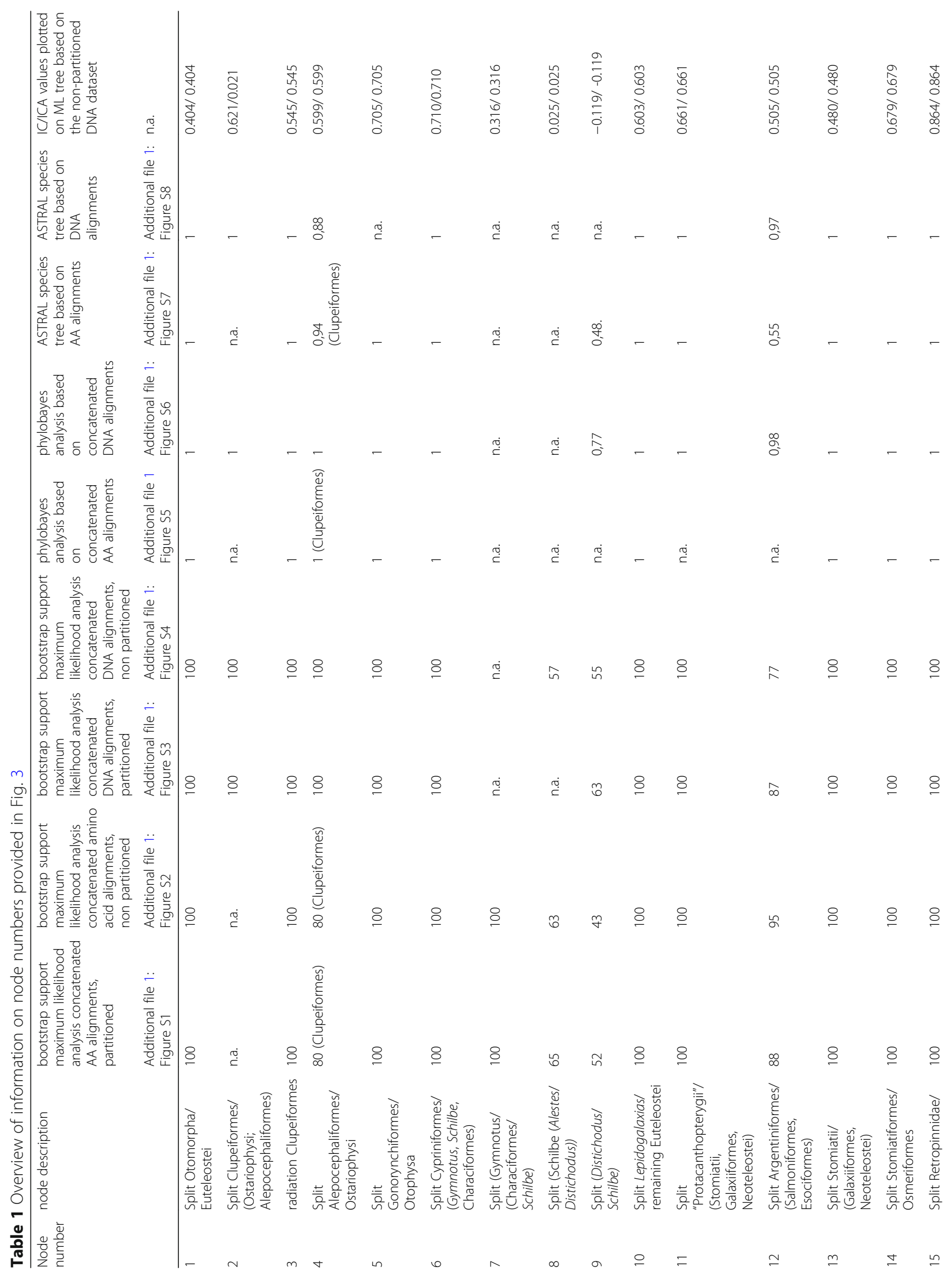


Straube et al. BMC Evolutionary Biology

(2018) 18:158

Page 8 of 17

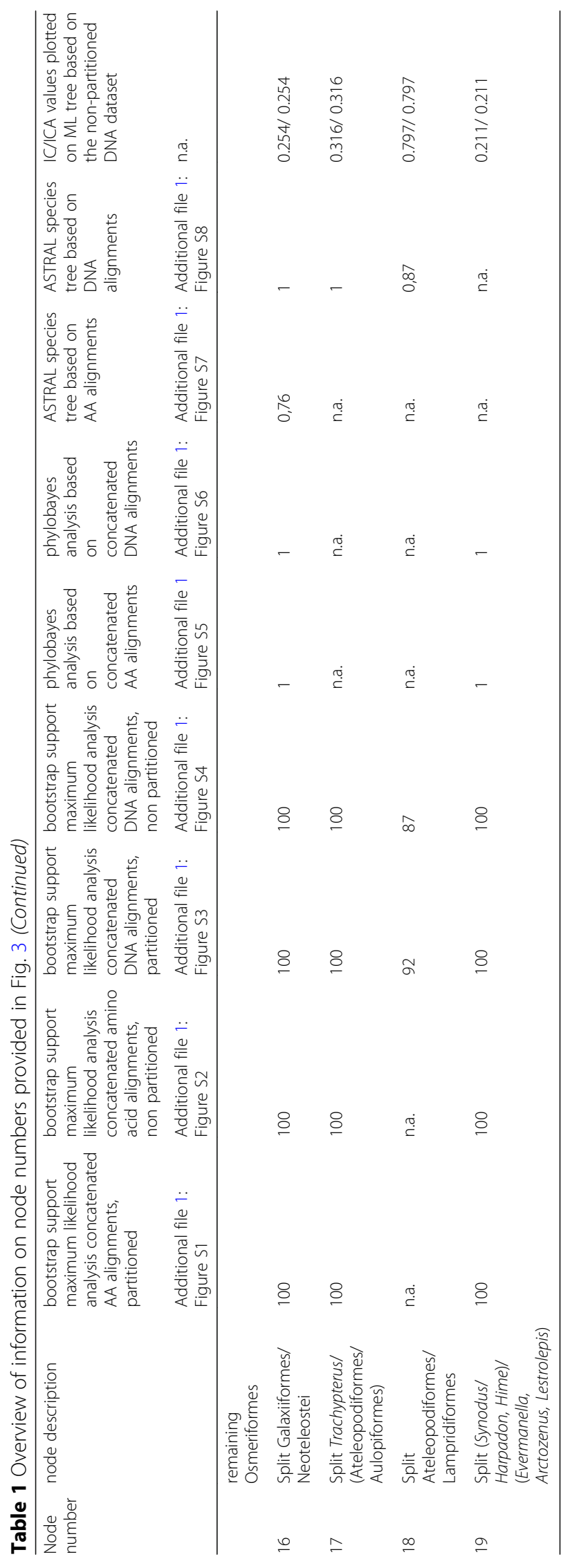


Galaxiiformes) appears paraphyletic in the analysis of the concatenated amino acid alignment (Additional file 1: Figure S2) using the Bayesian inference (Additional file 1: Figure S5). In these analyses, Esociformes are sister to a clade including Argentiniformes, Osmeriformes, Galaxiiformes, Stomiatiformes, and neoteleost fishes, while all other analyses reconstruct a phylogeny as shown in Fig. 3, however, node support values for the split are partially low (Table 1).

Within neoteleosts, our results show two possible cladograms. Either two clades, where Aulopiformes is sister to a clade comprising Ateleopodiformes and Trachypterus (Table 1, Additional file 1: Figures S3, S4, S8) or Trachypterus as sister to remaining neoteleost lineages included in this study (Table 1, Additional file 1: Figures S1, 2, unresolved in S5 and S6).

Except for few nodes, bootstrap and posterior node support values are high, i.e. above $95 \%$ or 0.95 , respectively (Table 1). Computed IC and ICA values [42, 45-47] do not indicate conflicting bipartitions except for the nodes, which will be discussed below and are also marked with low node support values (Table 1). The overall relative tree certainty is 0.48 indicating low incongruence among trees. The AU test performed in CONSEL [48-51] ranks the phylogenetic estimates based on the concatenated nucleotide datasets higher than all other bifurcating trees, where the tree estimate based on the partitioned nucleotide alignment ranks highest (Additional file 1: Table S4).

\section{Discussion}

\section{Molecular and morphological evidence for the Otomorpha}

All phylogenetic reconstructions performed in this study readily result in well-supported Otomorpha as sister clade to Euteleostei and include Alepocephaliformes, as previously found in molecular studies $[1-5,10]$. However, the phylogenetic placement of the alepocephaliforms within Otomorpha remains not completely ascertained as reflected in weak node support and low IC and ICA values indicating incongruence (Table 1). Future studies should include a denser taxon sampling covering the different inter- and intra-otomorph lineages to verify results presented herein.

Our review of hitherto proposed synapomorphic morphological characters in the light of the phylogenetic reconstruction (Fig. 3) indicates that morphological evidence supporting Otomorpha including Alepocephaliformes is presently limited. After taking into account previous reviews of morphological characters [6, 12, 13, 17, 26], nine characters have been discussed as possible apomorphies (see above) for Otomorpha. Three do not withstand thorough investigation, even without considering the inclusion of alepocephaliforms, i.e. the early ossification of the autopalatine which is apomorphic for clupeocephalans $[7,17]$, the ossified epicentrals, which are plesiomorphic [22], and the otoyphsic connection, which principally differs in clupeomorphs and ostariophysi $[18,23,24]$ in a way that no transitional states seem likely. For the latter, the fossil record and the condition in Gonorynchiformes further contradict a possible synapomorphic state. Therefore, six characters remain as candidates to characterize the Otomorpha without including alepocephaliforms: (1) parietals fused with extrascapulars, (2) anterior part of swim bladder with silvery peritoneum, (3) fusion of haemal spines anterior of preural centrum 2 with their centra from an early stage on, as well as three characters dealing with the caudal fin skeleton: (4) the absence of a united cartilaginous basis of hypurals 1 and 2, (5) fusion of hypural 2 with the compound centrum, and (6) the presence of a pleurostyl.

Discussing the six characters in Alepocephaliformes reveals the difficulties arising when analysing such a morphologically highly specialized taxon. Fig. 4 (A and B) shows the dorsal view on the posterior right part of the neurocranium in two alepocephalid species focusing on medial extrascapulars. The ossified canals of the occipital commisure can be interpreted as the remnants of extrascapulars. They are not fused with the parietals in any analysed alepocephalid species, exemplified in Fig. 4. This challenges the synapomorphic state of character 1. In Lecointre and Nelson [12], a fusion of the extrascapular with the parietal in two alepocephalids, i.e. Leptoderma and Rouleina is described. A more detailed sample of alepocephalid species is necessary to fully evaluate character 1 and clarify, if this poses a convergence in Leptoderma and Rouleina with clupeomorphs and ostariophysi or a reversal in other alepocephaliforms species. Alepocephaliformes lack a swim bladder, which is likely owed to their deep-sea inhabiting lifestyle. Therefore, the details of the swim bladder such as character 2 can generally not be analysed. This does not exclude the possibility, that this character is still a synapomorphy, as it may have been reduced in the course of adapting to deep-sea conditions and could well be present in the common ancestor.

Despite their tendency for a delayed ossification in development, alepocephaliforms show an early fusion of heamal spines with their centra anterior to preural centrum 2 (character 3) (Fig. 5b, c). Therefore, character 3 seems to be a valid apomorphy for otomorphs $[6,14,24]$. On the other hand, maybe due to the long persisting cartilages in alepocephaliform development, a continuous cartilaginous basis of hypurals 1 and 2 is clearly visible in Holtbyrnia and Normichthys (Fig. 5a-c) as well as Xenodermichthys and Maulisia. This state likely excludes character 4 as possible apomorphy for otomorphs. This cartilage also separates hypural 2 from the compound centrum avoiding a fusion (character 5). However, if the slow ossification sequence in 


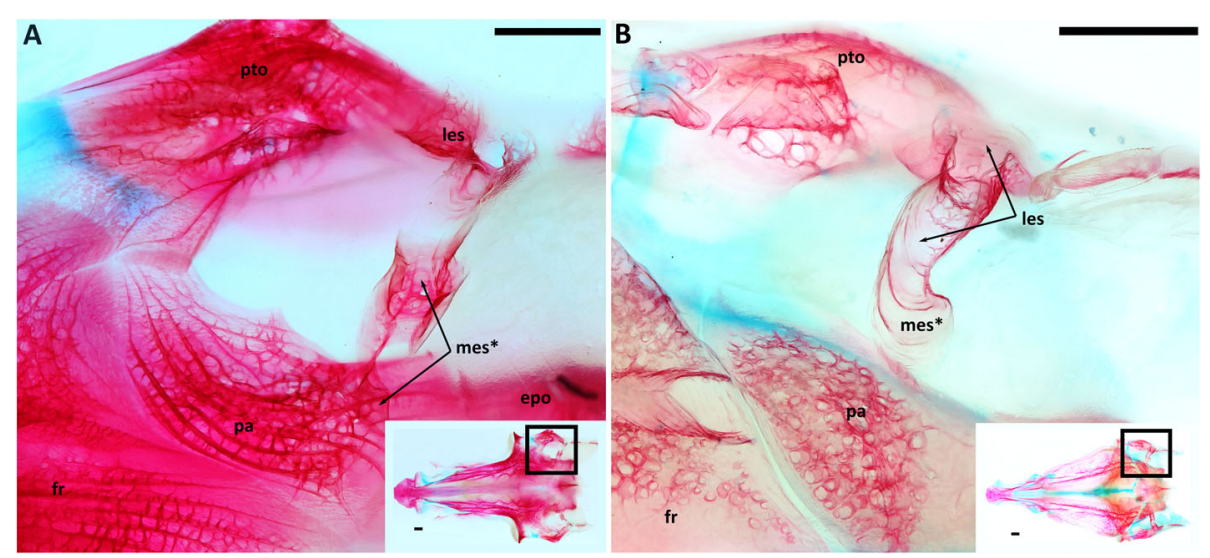

Fig. 4 Dorsal view on the lateral neurocranium with focus on medial extrascapular (marked with an arrow) and parietal (Character 2). Cartilages are blue and bones are red. a: Holtbyrnia anomala, $144 \mathrm{~mm} \mathrm{SL}$, b: Normichthys operosus, $97 \mathrm{~mm} \mathrm{SL}$. Abbreviations: epo, epioccipital; fr, frontal; les, lateral extrascapular; mes, medial extrascapular; pa, parietal; pto, pterotic. Scale bar =1 mm

alepocephaliforms is interpreted as apomorphic for this group, the situation in alepoecphaliforms could be the result of a reversal. In summary, the status of characters 4 and 5 remain questionable. The situation is clearer for the pleurostyl (character 6) which is clearly absent in alepocephaliforms (Fig. 5a-c). It is further absent from Denticeps (Clupeiformes, Fig. 5d), several fossil clupeiforms [52-54] and gonorynchiforms [25]. All this indicates that pleurostyles in Clupeoidei and Ostariophysi have convergently evolved [13, 14].

\section{Molecular and morphological evidence for otophysean interrelationships}

Figure 3 shows Ostariophysi splitting in two major clades where Gonorynchiformes are sister to the Otophysa (Characiformes, Cypriniformes, Gymnotiformes, and Siluriformes). Within Otophysa, Cypriniformes are sister to a clade comprising Characiformes Alestes and Distichodus as well as Gymnotus sp. representing the Gymnotiformes and Schilbe as a representative taxon of Siluriformes. Only recently, the complex phylogeny of this clade has been in the focus of phylogenomic level analyses $[32,33,55]$. A major point of discussion of these studies is the monophyly of Characiformes. While [32, 55] present a phylogeny in congruence to morphological data, [33] do not recover Characiformes as monophyletic.

In our study, the analyses of concatenated amino acid data (Table 1, Additional file 1: Figures S1, S2) reflect the interrelationships of Gymnotus and Schilbe as sister clade to monophyletic Characiformes. In all other analyses these interrelationships are mixed up showing for example a sister group relationship of Distichodus (Characiformes) and Schilbe (Siluriformes) or remain unresolved (Additional file 1: Figures S3, S4, S5, S6, S7, S8). We conclude that we did not sample enough variation of these lineages capturing insufficient phylogenetic signal for resolving these interrelationships with confidence. Figure 3 shows a phylogeny derived from the maximum likelihood analysis of concatenated nucleotide alignments, which were identified as significantly more likely compared to other phylogenetic estimates by the AU Test [48-51] (Additional file 1: Table S4). However, only the phylogenetic reconstructions based on the concatenated amino acids (Additional file 1: Figure S1 and S2) align with morphological synapomorphies suggested to characterize these clades. Regarding suggested synapamorphic characters, the Weberian apparatus was considered to characterize the Otophysa as taxonomic unit by Rosen and Greenwood [23] as well as Greenwood [56]. Further, four major clades (i.e. Cypriniformes, Characiformes, Gymnotiformes and Siluriformes) and their interrelationships were strongly supported by several morphological characters considered apomorphic $[6,26]$. Contrasting, results of previous molecular phylogenetic studies did not support the monophyly of characiforms [33, 57-61], or the sister-group relation of siluriforms and gymnotiforms, which is strongly supported by several morphological apomorphies [24].

\section{Phylogeny of Euteleostei}

Our analyses clearly recover monophyletic Euteleostei. So far, only three apomorphies were listed in a previous morphological review for the Euteleostei [6]: (1) a stegural, (2) caudal median cartilages, and (3) a unique pattern of supraneural shape and development. The first two characters are challenged by alepocephaliforms clustering among Otomorpha. Alepocephaliforms show a stegural, which is a uroneural 1 with anterodorsal membranous outgrowth [6], and caudal median cartilages (Fig. 5a-c). Presently only the unique supraneural pattern (pattern 2 in Johnson and Patterson [13]) remains as synapomorphic character for 


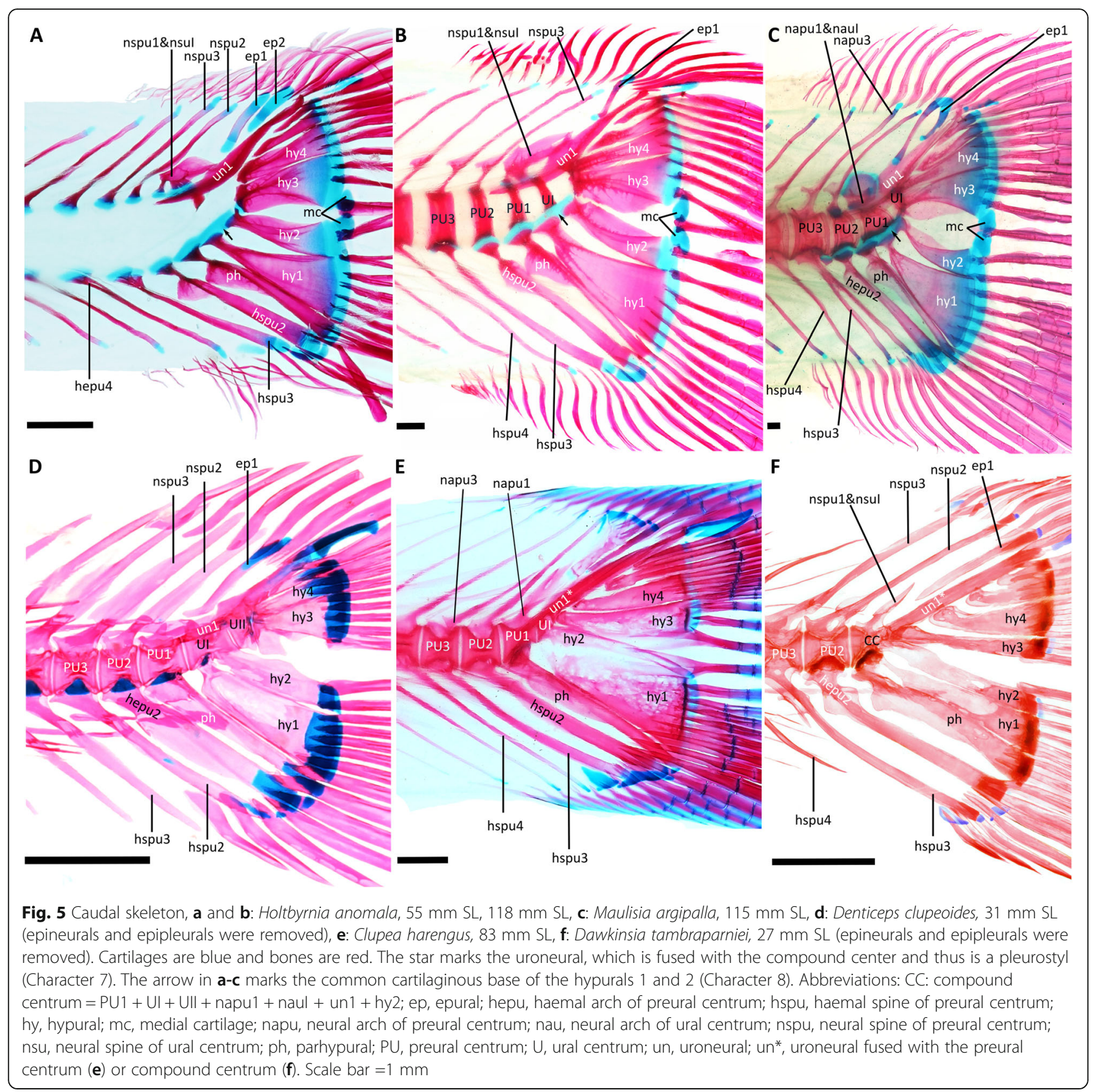

the Euteleostei, as alepocephaliforms do not show the respective character state.

The Lepidogalaxias lineage forms the sister taxon to all remaining euteleost fishes. This endemic West-Australian freshwater species unites several unique morphological characters and may actually be of key importance to understand the early evolution and extant diversity of euteleosts. Its unexpected phylogenetic position further calls morphological features into question, which were used to characterize interrelationships of Lepidogalaxias and galaxiids [29], as these characters are shared between both taxa, although they are showing no close phylogenetic relationship in any molecular phylogenetic analysis $([1-3,5,29,55,61]$, this study). This leads us to conclude that some of these characters are based on convergent evolution, while others may indeed be of plesiomorphic state. The phylogenetic position of galaxiids remains enigmatic. While Betancur- $R$ et al. [1] suggest them to be part of the supergroup Protacanthopterygii, Near et al. [5] suggest Galaxiiformes to be the sister to all neoteleost lineages with high node support. Recently, in their phylogenomic level study, Hughes et al. [55] report on some cases of incongruence of gene trees and conflicting phylogenetic hypothesis. Here, Galaxiiformes form the 
sister group to neoteleosts in all analyses with high support. An estimate ICA value of 0.254 for this split suggests less incongruence compared to 0.078 in [55]. Our results are therefore in favour of Hughes et al.'s [55] hypothesis $\mathrm{H} 1$, which may be caused by novel sequencing information from the genus Lovettia (Aplochitonidae, respectively Aplochitoninae) representing the sister group of all other galaxiids [62]. Thus we suggest Galaxiiformes to form the sister group to neoeteleost fishes and that thus Protacanthopterygii do not include Galaxiiformes. They are likely of major importance for understanding the evolution of extant Neoteleostei. Development of characters through ontogeny of both lineages are crucial to identify synapomorphies, which may allow for an update for the morphological synapomorphies of neoteleost fishes.

As aforementioned, Protacanthopterygii sensu Betancur- $R$. et al. $[1,2]$ cannot be recovered, as Galaxiiformes do not cluster along with other Prothacanthopterygii in any of our analysis. Fig. 3 shows Argentiniformes as sister to a clade comprising Esoci- and Salmoniformes. This sister group relationship cannot always be recovered, as indicated by low node support via bootstrapping as well as low IC values indicating incongruence (Fig. 3, Table 1). The Bayesian inference analysis of the concatenated amino acid alignment contradicts these interrelationships and suggest Argentiniformes as sister to Stomiatii, Galaxiiformes and Neoteleosts (Table 1, Additional file 1: Figure S5). Contrasting, all other analyses of both amino acid and DNA based gene trees align with results from the maximum likelihood analysis from the concatenated DNA and alignment shown in Fig. 3 (Table 1, Additional file 1: Figures S1, S2, S3, S4, S6, S7, S8). Betancur-R. et al. [2] and Hughes et al. [55] discuss the difficult situation for Protacanthopterygii and characterize their classification as sedis mutabilis [2]. Due to the very different phylogenetic hypothesis published for the group, morphological evidence supporting the group is virtually lacking. Candidate characters are cartilaginous epicentrals, and simple (not forked) epineurals and epipleurals [6], which are subject of ongoing studies.

Stomiatii sensu Betancur-R. et al. [1, 2] are recovered in all our analyses. The sister group relationship of a mostly coastal marine and coastal freshwater lineage, the Osmeriformes, and an exclusively marine and comparably highly diverse deep-sea lineage, the Stomiatiformes, is noteworthy and somewhat parallels the relationship of Alepocephaliformes and clupeomorphs. Stomiatiformes share morphological characters of neoteleost fishes, prompting synapomorphies for the latter group. These characters mainly refer to the highly derived branchial musculature including a new muscle, the retractor dorsalis, present in Stomiatiformes and neoteleosts [13, 63-65]. Morphological evidence for a relationship of Osmeriformes and Stomiatiformes is presently still lacking. The family Retropinnidae contains several freshwater and brackish water species. Our phylogenetic reconstruction shows that Retropinna is sister to all other osmeriforms (Fig. 3). All phylogenetic analyses performed in this study result in a well-supported sister group relationship of Stomiatii to the galaxiiformneoteleost clade (Table 1, Fig. 3, Additional file 1: Figure S1-8). Morphological synapomorphies for this clade are still lacking.

However, our resolution of some deep phylogenetic nodes within the Clupeocephalan phylogeny will help allowing for reviewing morphological apomorphies and identifying candidate characters for the description and subsequent classification in the context of clades presented in this study.

\section{Conclusions}

Molecular phylogenies including the tree reconstruction presented herein have called numerous morphological apomoprhies of clades into question, as topologies derived from morphology and molecular data differ significantly. The interpretation of suggested morphological synapomorphies of otomorph fishes is strongly affected by the inclusion of deep-sea inhabiting Alepocephaliformes. Our revision of these potential synapomorphies reveals that only a single character of nine characters in total can be flagged as synapomorphy valid for otomorphs. Three further characters remain possible apomorphies since their status cannot be evaluated without ambiguity in Alepocephaliformes.

Our phylogenetic estimate of Euteleost lineages shows that Protacanthopterygii, sensu Betancur-R. et al. [2] comprising Esoci-, Salmoni-, Argentini-, and Galaxiiformes, cannot be recovered, as Galaxiiformes appear to be the sister to all neoteleost fishes and further, a common ancestor of Salmoni-, Esoci and Argentiniformes is not well supported. It is noteworthy that another study contemporaneously aiming to solve the actinopterygian phylogeny with a very similar approach as the analysis presented herein, results in the same challenging nodes in their phylogenetic estimate [55]. Some splits remain uncertain, as e.g. the composition and phylogenetic placement of Protacanthopterygii or the phylogenetic placement of Alepocephaliformes, a group not included in [55]. Our efforts to reconstruct deep phylogenetic nodes based on a phylogenomic level dataset of clupeocephalan fishes still reveals problematic divergence estimates and calls for the application of phylogenomic methods on datasets with an enhanced taxon sampling, which can strengthen some of the phylogenetic hypothesis presented herein. Regarding morphology, data on possible characters for several nodes in the present 
clupeocephalan tree are scarce. Therefore, subsequent morphological studies are required to understand character evolution, evolutionary driving forces and origin of species diversity in extant clupeocephalans.

\section{Methods}

Material

The major part of samples was collected during field trips and comprise muscle tissue or fin clips, respectively. The sampling aims for covering the major teleost lineages with a focus on Clupeocephala where neoteleosts, elopomorphs and osteoglossmorphs serve as an outgroup. Please see Additional file 1: Table S1 for an overview of samples analysed.

\section{Methods}

\section{Bait design}

To retrieve blueprints for bait sequences, we used the online resource Evolmarkers $[66,67]$ to search for putative ortholog exon loci in publicly available reference genomes. In a first step, we searched the genome of the zebra fish, Danio rerio (Cypriniformes), for single-copy loci using standalone BLAST [34]. In a second step, the results were subsequently BLASTed [34] against further available bony fish genomes, at the time of bait design comprising Anguilla anguilla, Oryzias latipes, Tetraodon nigroviridis, Lepisosteus oculatus, Gadus morhua, Gasterosteus aculeatus and Oreochromis niloticus. Finally, only exon sequences with a single BLAST [34] hit in all analysed genomes were used for bait design. Custom RNA baits were manufactured by Arbor Biosciences (Ann Arbor, Michigan, USA) with a length of 120 nucleotides and 60 nucleotides overlap after padding sequence lengths totaling 39,049 unfiltered baits with a $2 \times$ flexible tiling density. After removing all baits with any soft-masked sequence, 38,318 baits were put into production.

\section{Library preparation}

Genomic DNA was extracted from tissue samples listed in Additional file 1: Table S1 using the Machery \& Nagel blood and tissue kit ${ }^{\circ}$. The DNA content of the final eluate was measured using a $\mathrm{Qbit}^{\circ}$ Fluorometer (Life Technologies) applying the broad range kit. Thereafter, $130 \mu \mathrm{l}$ with a concentration of at least $3 \mathrm{ng} /$ $\mu \mathrm{l}$ DNA were used for shearing the DNA to $\sim 500 \mathrm{bp}$ using a Covaris $^{\circ}$ Sonicator. Shearing success was checked using gel-electrophoresis. The following steps for Illumina (Illumina, Inc., San Diego, CA) library constructions are based on $\mathrm{Li}$ et al. [68] and comprise a size selection step for fragments $>500 \mathrm{bp}$, blunt end repair using polymerase, adaptor ligation, fill-in and a final amplification of libraries using the $\mathrm{KAPA}^{\circ}$ library amplification kit. DNA content of libraries was measured using a $\mathrm{Qbit}^{\circ}$ fluorometer applying the high sensitivity kit and further checked with gel-electrophoresis to check the size distribution of fragments.

\section{Target capture}

For the performance of interordinal target capture, amplified libraries from step 2.2 served as starting point for hybrid enrichment. All steps follow the protocol provided in Li et al. [68]. Summarizing, library fragments are hybridized to RNA baits, remaining fragments and unintentionally hybridized fragments are washed off. During hybridisation, blocking oligos are preventing adaptor to adaptor ligation, while human cot DNA serves to avoid repetitive elements to cause non-specific binding. We applied a touch down hybridisation with decreasing hybridisation temperature from $65^{\circ}$ to $50{ }^{\circ} \mathrm{C}$ in steps of $11 \mathrm{~h}$ totaling $36 \mathrm{~h}$ of hybridisation. The captured library is again amplified, size selected [69] and used as a starting point for a second round of capture, which is shown to increase the number of genes captured [68, 70].

During the final amplification step, individual sequencing indices are implemented to the adaptors allowing for de-multiplexing of reads after sequencing on an Illumina $\mathrm{MiSeq}^{\circ}$ instrumentation. We aimed for an average coverage of 6.6 million paired-end 250 basepair reads per sample.

\section{Data analysis}

Recovery of exon sequence alignments of phylogenetically informative loci Sequencing reads were first checked for quality and low quality reads were excluded from further analysis with a cut-off value of 20. Adaptors were trimmed from reads using Trimgalore vers 03.07 $[71,72]$. Thereafter, we followed the analysis pipeline introduced for target capture data in Yuan et al. [37]. Trimmed reads are first searched for replicate sequences, which are subsequently removed. For that, the first $20 \mathrm{bp}$ of both reads are compared, if identical, they are removed. In a next step, the reads are BLASTed [34] against the bait sequences to sort the reads into corresponding gene bins. Next, reads are de-novo assembled into contigs using Trinity vers. 2.2.0 [73]. Output contigs are then separated into folders containing one or more than one contig. Where Trinity was creating more than a single contig sequence, Geneious ${ }^{\circ}$ R7 was used to further assemble multiple contigs in an effort to create even longer contig sequences. For retrieving the best sequences of each gene in comparison to the bait sequences (query sequences were the bait sequences derived from the Danio rerio genome), we predicted the frame of each query sequence using a custom python script (predict.frame.py), which is available for download at the Dryad data 
depository [39], and trimmed stop codons from it. Subsequently, contigs were translated into amino acids. All contigs were reciprocally blasted against the query sequences to check for homologs, i.e. contigs showing the best blast hit out of the target region were excluded from further analytical steps. As we are performing target capture on inter-ordinal level, the rate of gene losses or duplications is unknown, therefore single copy genes identified in Evolmarkers [66, 67] are not necessarily single copy in phylogenetically distant taxa. Therefore, contigs, which did not pass the reciprocal blast screening, were excluded from further analyses. Finally, intron inserted sequences were merged and subsequently translated to amino acids. We used customized Perl scripts to batch align each gene bin file containing all captured taxa and the bait sequence using MAFFT [74, 75]. As cross-contamination poses a problem in NGS datasets (e.g. [76]), possible cross-contamination were checked using a custom perl-script [39], which uses p-distances computed from single loci alignments and information on taxon groups assumed to be closely related. These are then compared with more distantly related taxa. Potential cross-contamination is indicated by extremely small p-distances (equal to or smaller than 0.002) between distantly related taxa (Additional file 1: Table S2). Although p-distance between conserved loci can be extremely small between distantly related taxa, conservation cannot be ubiquitous among all loci. Thus, there is no cross-contamination between a pair of taxa, if percentage of potential cross-contamination between them among all loci is extremely low. Subsequently, cleaned single loci were concatenated using Geneious ${ }^{\circ}$ R7. The concatenated sequences were checked for phylogenetically most informative loci using the software Matrix Reduction [35], which is based on the treelikeness computed for single loci [36]. After extracting 838 most informative loci [39], we used customized Perl scripts to batch align each gene bin file containing all captured taxa and the bait sequence using MAFFT [74, 75]. As an additional check for orthology, the 838 loci identified with the Matrix reduction software, were analysed using Orthograph vers. 0-6-3-1 [38] and the custom script reblast.pl (Additional file 1: Table S3). Applying the latter approach, another four loci were eliminated from the dataset. Finally, five loci were excluded as they contained less than four sequences.

\section{Phylogenetic analyses Concatenated datasets}

Concatenation was performed in Geneious R7 on 829 phylogenetically informative loci suggested from the MARE $[35,36]$ analysis (Additional file 1 ). We analysed two datasets, i.e. the amino acid alignments as well as the DNA alignments. For finding best-fitting partitions for the concatenated datasets, Partition finder vers. 2.1.1 [40-42] was used. A phylogenetic analysis based on maximum likelihood was performed in RAxML vers. 8.2.4 [42] incorporating the best-fitting partitioning schemes. RAxML [42] settings were applying the GTR GAMMA substitution model. Bootstrapping was halted automatically [77] using the fast hill-climbing algorithm.

As an alternative, we computed a phylogenetic tree using a Bayesian inference applying the CAT dirichlet process $[78,79]$ implemented in PhyloBayes vers. 4.1c [43]. Two chains were run in parallel and checked for convergence using the tracecomp and bpcomp scripts provided in PhyloBayes.

All abovementioned analyses were performed in CIPRES [80].

\section{Coalescence analysis}

For a comparison of phylogenies computed from the concatenated dataset and a coalescence-based approach, we further performed maximum likelihood tree searches on single DNA and amino acid loci alignments using RAxML [42] on batch for attaining a collection of gene trees from both amino acid and DNA datasets. Those were subsequently used for estimating the species tree in ASTRAL vers. 4.10.12 [44].

\section{Computing tree certainty and performing $A U$ test}

We computed internode certainty (IC/ ICA) and tree certainty (TC/ TCA) values $[45,46]$ from partial gene trees from the gene trees depicted from the coalescence analysis as implemented in RAxML [42, 47] using the best tree resulting from the maximum likelihood analysis of the concatenated and best-partitioned amino acid alignments. This step was used to evaluate incongruence among trees.

For testing for significant differences of species trees and fully bifurcating trees based on concatenated alignments, we performed an AU test in CONSEL [48-51].

\section{Morphological comparative material}

Cleaned and double stained collection specimen:

Osteoglossiformes. Osteoglossidae: Osteoglossum bicirrhosum (Cuvier, 1829): DMM IE/11035, 95.5 mm SL.

Elopiformes. Elopidae: Elops senegalensis Regan, 1909: DMM IE/11008, $61.3 \mathrm{~mm}$ SL.

Clupeiformes. Denticipitidae: 3 Denticeps clupeoides Clausen, 1959: DMM IE/11417, IE11420, 29.2-41.1 mm SL. Clupea harengus Linnaeus, 1758: DMM IE/ 11,029 $83.1 \mathrm{~mm}$ SL.

Alepocephaliformes. Alepocephalidae: Alepocephalus bicolor Alcock, 1891: DMM IE/9602, 192 mm SL, Xenodermichthys copei (Gill, 1884) DMM IE/10190, 110.1 mm SL. Platytroctidae: 5 Holtbyrnia anomala Krefft, 1980: DMM IE/10079, IE 10079, IE 6145, IE 4885, $55.99 \mathrm{~mm} \mathrm{-}$ 
144.4 mm SL; Maulisia argipalla Matsui \& Rosenblatt, 1979: DMM IE/10459, 115.6 mm SL. Normichthys operosus Parr, 1951, DMM IE/11040, 97.1 mm SL; Searsia koefoedi Parr 1937: DMM IE/10191, 117.6 mm SL.

Gonorynchiformes. Gonorynchidae: Gonorynchus abbreviates Temminck \& Schlegel, 1846, DMM IE/11730, 84,2 mm SL; Chanidae: Chanos chanos (Forsskl, 1775): DMM IE/11010, 72.18 mm SL; Kneridae: Kneria stappersii Boulenger, 1915, DMM IE/12025, 26.4 mm SL.

Cypriniformes. Cyprinidae: 2 Dawkinsia tambraparniei (Silas, 1954): DMM IE/12072, 27.8 mm SL, 28.6 mm SL.

Argentiniformes. Argentinidae: Argentina silus (Ascanius, 1775): DMM IE/11033, 103.2 mm SL; Bathylagidae: Bathylagus euryops Goode \& Bean, 1896: DMM IE/11034, $96.3 \mathrm{~mm} \mathrm{SL}$.

Osmeriformes. Osmeridae: Osmerus eperlanus (Linnaeus, 1758), DMM IE/11090, 36.5 mm SL.

Salmoniformes: Thymallidae: Thymallus thymallus (Linnaeus, 1758) DMM IE/11820, 99.5 mm SL.

The specimens were cleared and double stained following [81, 82]. Specimens were transferred into 98\% ethanol. Afterwards, cartilage was stained with Alican blue in 1:4 acetic acid and ethanol-solution for maximally $48 \mathrm{~h}$. Thereafter, the specimens were transferred via a decreasing alcohol concentration in digestion solution with trypsin. As soon as specimens were cleared, the pigmentation of the skin was eliminated by a bleach bath of potassium hydroxide solution and addition of hydrogen peroxide. Subsequently, bones were stained with Alizarin-red. Finally, specimens were transferred into glycerine for increasing the transparency.

The dissected parts of the specimens were photographed with a Canon EOS 50D with a Sigma $105 \mathrm{~mm}$ lens and the software EOS Utility 3.0 (Canon). Stacking of images for obtaining advanced and extended focus images were done with software Helicon Focus 6. The images were edited in GIMP 2.8 and were compiled in Inkscape 0.92.1.

\section{Additional file}

Additional file 1: Overview of samples, analyses protocols, and tree Figures S1-S8. (PDF $772 \mathrm{~kb}$ )

\section{Acknowledgements}

We would like to acknowledge several colleagues for their kind help with sampling: Mark Adams (South Australian Museum), Katherine Pearson Maslenikov (Burke Museum), Samuel Iglésias (Musée nationale d'Histoire naturelle), Alastair Graham (Commonwealth Scientific and Industrial Research Organisation), Ulrich Schliewen, Frederic Schedel, and Dirk Neumann (all Bavarian State Collection of Zoology). Further, we would like to express our sincere thanks to Aurélien Tellier, Saurabh Pophaly, and Hanna Märkle (Technical University Munich) for clustering, David Langenberger (EcSeq), Mario Fasöld (EcSeq) and Jörg Lesch (Lesch IT) for IT support.

\section{Funding}

This work was funded by the VolkswagenStiftung within the focal point program "Forschung in Museen" AZ-88 353 to TM and NS.

\section{Availability of data and materials}

The data sets supporting the results of this article are available in the Dryad data repository, doi:https://doi.org/10.5061/dryad.7b19f33; https:// datadryad.org/review?doi=doi:10.5061/dryad.7b19f33.

\section{Authors' contributions}

TM and NS designed the study. Laboratory work was carried out by NS and MM. NS, CL, HY analyzed the data. NS, TM, MM, CL wrote and drafted the manuscript. All authors read and approved the final version of the manuscript.

Ethics approval and consent to participate

Not applicable.

\section{Consent for publication}

Not applicable.

\section{Competing interests}

The authors declare that they have no competing interests.

\section{Publisher's Note}

Springer Nature remains neutral with regard to jurisdictional claims in published maps and institutional affiliations.

\section{Author details}

${ }^{1}$ Institut für Zoologie \& Evolutionsbiologie, Friedrich-Schiller-Universität Jena, Erbertstraße 1, 07743 Jena, Germany. ${ }^{2}$ Zoologische Staatssammlung München, Staatliche Naturwissenschaftliche Sammlungen Bayerns, Münchhausenstraße 21, 81247 Munich, Germany. ${ }^{3}$ Key Laboratory of Exploration and Utilization of Aquatic, Genetic Resources, Shanghai Ocean University, Ministry of Education, Shanghai 201306, China. ${ }^{4}$ Deutsches Meeresmuseum, Katharinenberg 14-20, 18439 Stralsund, Germany.

Received: 26 August 2017 Accepted: 26 September 2018

Published online: 23 October 2018

References

1. Betancur-R R, Broughton RE, Wiley EO, Carpenter K, López JA, Li C, Holcroft $\mathrm{NI}$, Arcila D, Sanciangco M, Cureton JC II, Zhang F, Buser T, Campbell MA, Ballesteros JA, Roa-Varon A, Willis S, Borden WC, Rowley T, Reneau PC, Hough DJ, Lu G, Grande T, Arratia G, Ortí G. The tree of life and a new classification of bony fishes. PLOS Currents. 2013. https://doi.org/10.1371/ curents.tol.53ba26640dfoccaee75bb165c8c26288.

2. Betancur-R R, Wiley EO, Arratia G, Acero A, Bailly N, Mya M, Lecointre G, Ortí G. Phylogenetic classification of bony fishes. BMC Evol Biol. 2017. https://doi. org/10.1186/s12862-017-0958-3.

3. Lavoué S, Miya M, Poulsen JY, Møller PR, Nishida M. Monophyly, phylogenetic position and inter-familial relationships of the Alepocephaliformes (Teleostei) based on whole mitogenome sequences. Mol Phylogenet Evol. 2008;47:1111-21.

4. Lavoué S, Miya M, Inoue JG, Saitoh K, Ishiguro NB, Nishida M. Molecular systematics of the gonorynchiform fishes (Teleostei) based on whole mitogenome sequences: implications for higher-level relationships within the Otocephala. Mol Phylogenet Evol. 2005. https://doi.org/10.1016/j.ympev. 2005.03.024

5. Near TJ, Eytan Rl, Dornburg A, Kuhn KL, Moore JA, Davis MP, Wainwright PC, Friedman M, Leo Smith W. Resolution of ray-finned fish phylogeny and timing of diversification. PNAS. 2012. https://doi.org/10.1073/pnas. 1206625109

6. Wiley EO, Johnson GD. A teleost classification based on monophyletic groups. In: Nelson JS, Schultze HP, MVH W, editors. Origin and phylogenetic interrelationships of Teleosts. München: Verlag Dr. F. Pfeil; 2010. p. 123-82.

7. Arratia G. The Clupeocephala re-visited: analysis of characters and homologies. Rev Biol Mar Oceanog. 2010;45(Suppl 1):635-57.

8. Ishiguro NB, Miya M, Nishida M. Basal euteleostean relationships: a mitogenomic perspective on the phylogenetic reality of the "Protacanthopterygii". Mol Phylogenet Evol. 2003;27:476-88.

9. Lavoué S, Miya M, Kawaguchi A, Yoshino T, Nishida M. The phylogenetic position of an undescribed paedomorphic clupeiform taxon: mitogenomic evidence. Ichthyol Res. 2008;55:328-34. 
10. Poulsen JY, Møller PR, Lavoué S, Knudsen SW, Nishida M, Miya M. Higher and lower-level relationships of the deep-sea fish order Alepocephaliformes (Teleostei: Otocephala) inferred from whole mitogenome sequences. Biol J Linn Soc. 2009. https://doi.org/10.1111/j.1095-8312.2009.01323.x.

11. Greenwood PH, Rosen DE. Notes on the structure and relationships of the alepocephaloid fishes. Am Mus Novit. 1971;2473:1-41.

12. Lecointre G, Nelson G. Clupeomorpha, sister-group of Ostariophysi. In: Stiassny MLJ, Parenti LR, Johnson GD, editors. Interrelationships of fishes. San Diego: Academic Press; 1996. p. 193-207.

13. Johnson GD, Patterson C. Relationships of lower euteleostean fishes. In: Stiassny MLJ, Parenti LR, Johnson GD, editors. Interrelationships of fishes. San Diego: Academic Press; 1996. p. 251-332.

14. Arratia G. Basal teleosts and teleostean phylogeny. Palaeo Ichthyologica. 1997;7:1-168.

15. Arratia G. The monophyly of Teleostei and stem-group teleosts. Consensus and disagreements. In: Arratia G, Schultze HP, editors. Mesozoic fishes 2. Systematics and fossil record. München: Verlag Dr. Friedrich Pfeil; 1999. p. 265-334.

16. Arratia G, Schultze HP. Palatoquadrate and its ossifications: development and homology within osteichthyans. J Morphol. 1991;208:1-81.

17. Arratia $G$. The varasichthyid and other crossognathiform fishes, and the break-up of Pangaea. In: Cavin L, Longbottom A, Richter M, editors. , vol. 295. London: Geological society, Special Publications; 2008. p. 71-92.

18. Grande L. Recent and fossil clupeomorph fishes with materials for revision of the subgroups of clupeids. Bull Am Mus Nat Hist. 1985;181:231-72.

19. Gayet M. Ramallichthys, Gayet du Cénomanien inferieur marin de Ramallah (Judée), une introduction aux relations phylogénétiques des Ostariophysi. Mém Mus Natl Hist Nat Ser. 1986;51:21-31.

20. Daget J. Le cráne des téléostéens. Mém Mus Nat Hist Nat Ser A. 1964;31:163-342.

21. Roberts T. Osteology and relationships of characoid fishes, particularly the genera Hepsetus, Salminus, Hoplias, Ctenolucius, and Acestrorhynchus. Proc Calif Acad Sci. 1969;36:391-500

22. Blot J. Les Apodes fossiles du Monte Bolca. Stud. Ric. Giacimenti Terziari di Bolca, Vol. 3, Fasc. 1. Verona: Museo Civico di Storia Naturale; 1978.

23. Rosen DE, Greenwood PH. Origin of the Weberian apparatus and the relationships of ostariophysan and gonorynchiform fishes. Amer Mus Novit. 1970;2428:1-25.

24. Fink S, Fink WL. Interrelationships of ostariophysan fishes (Teleostei). Zool J Linnean Soc. 1981;72:297-358.

25. Grande T, Arratia G. Morphological analysis of the gonorynchiform postcranial skeleton. In: Grande T, Poyato-Ariza FJ, Diogo R, editors. Gonorhychiformes and Ostariophysan Relationships: a Comprehensive Review. Enfield: Science Publishers; 2010. p. 39-71.

26. Fink S, Fink WL. Interrelationships of ostariophysan fishes. In: Stiassny ML, Parenti LR, Johnson GD, editors. Interrelationships of fishes. San Diego: Academic Press; 1996. p. 209-49.

27. Monod T. Le complexe urophore des poissons téléostéens. Mém Dakar: Inst Found Afr noire; 1968.

28. Fujita K. The caudal skeleton of Teleostean fishes. Tokai: University Press; 1990

29. Li J, Xia R, McDowall RM, Lopez JA, Lei GC, Fu CZ. Phylogenetic position of the enigmatic Lepidogalaxias salamandroides with comment on the orders of lower euteleostean fishes. Mol Phyl Evol. 2010;57:932-6.

30. Williams RRG. Bones and muscles of the suspensorium in the galaxioids and Lepidogalaxias salamandroides (Teleostei: Osmeriformes) and their phylogenetic significance. Rec Aust Mus. 1997. https://doi.org/10.3853/j. 0067-1975.49.1997.1263.

31. Mirande JM. Combined phylogeny of ray-finned fishes (Actinopterygii) and the use of morphological characters in large-scale analyses. Cladistics. 2016; 33:333-50.

32. Arcila D, Ortí G, Vari R, Armbruster JW, Stiassny ML, Ko KD, Sabaj MH, Lundberg J, Revell LJ, Betancur-R R. Genome-wide interrogation advances resolution of recalcitrant groups in the tree of life. Nat Ecol Evol. 2017. https://doi.org/10.1038/s41559-016-0020.

33. Chakrabarty P, Faircloth BC, Alda F, Ludt WB, McCahan CD, Near TJ, Dornburg A, Albert JS, Arroyave J, Stiassny MLJ, Sorenson L, Alfaro ME. Phylogenomic systematics of ostariophysan fishes: ultraconserved elements support the surprising non-monophyly of Characiformes. Syst Biol. 2010. https://doi.org/10.1093/sysbio/syx038.

34. Altschul SF, Gish W, Miller W, Myers EW, Lipman DJ. Basic local alignment search tool. J Mol Biol. 1990;215:403-10.

35. Meyer B, Meusemann K, Misof B: MARE. MAtrix REduction - A tool to select optimized data subsets from supermatrices for phylogenetic inference. 2017 https://www.zfmk.de/de/forschung/forschungszentren-und-gruppen/mare Accessed 13 Jan 2017.

36. Misof B, Meyer B, von Reumont BM, Kück P, Misof K, Meusemann K. Selecting informative subsets of sparse supermatrices increases the chance to find correct trees. BMC Bioinformatics. 2013. https://doi.org/10.1186/1471-2105-14-348.

37. Yuan H, Jiang J, Jiménez FA, Hoberg EP, Cook JA, Galbreath KE, Li C. Target gene enrichment in the cyclophyllidean cestodes, the most diverse group of tapeworms. Mol Ecol Resour. 2016;16:1095-106.

38. Petersen M, Meusemann K, Donath A, Dowling D, Liu S, Peters RS, Podsiadlowski L, Vasilikopoulos A, Zhou X, Misof B, Niehuis O. Orthograph: a versatile tool for mapping coding nucleotide sequences to clusters of orthologous genes. BMC Bioinformatics. 2017. https://doi.org/10.1186/s12859-017-1529-8.

39. Straube N, Li C, Mertzen M, Yuan H, Moritz T (2018) Data from: A phylogenomic approach to reconstruct interrelationships of main clupeocephalan lineages with a critical discussion of morphological apomorphies. doi:https://doi.org/10.5061/dryad.7b19f33.

40. Lanfear R, Calcott B, Kainer D, Mayer C, Stamatakis A. Selecting optimal partitioning schemes for phylogenomic datasets: a comparison of clustering methods. BMC Evol Biol. 2014. https://doi.org/10.1186/1471-2148-14-82.

41. Lanfear R, Frandsen PB, Wright AM, Senfeld T, Calcott B. PartitionFinder 2: new methods for selecting partitioned models of evolution formolecular and morphological phylogenetic analyses. Mol Biol Evol. 2016. https://doi. org/10.1093/molbev/msw260.

42. Stamatakis A. RAxML version 8: a tool for phylogenetic analysis and postanalysis of large phylogenies. Bioinformatics. 2014. https://doi.org/10.1093/ bioinformatics/btu033.

43. Lartillot N. PhyloBayes home page. 2017 http://.phylobayes.org. Accessed 23 Mar 2017

44. Mirarab S, Reaz R, Bayzid MS, Zimmermann T, Swenson MS, Warnow T. ASTRAL: genome-scale coalescent-based species tree estimation. Bioinformatics. 2014. https://doi.org/10.1093/bioinformatics/btu462.

45. Salichos L, Rokas A. Inferring ancient divergences requires genes with strong phylogenetic signals. Nature. 2013;497:327-31.

46. Salichos L, Stamatakis A, Rokas A. Novel information theory-based measures for quantifying incongruence among phylogenetic trees. Mol Biol Evol. 2014:31:1261-71.

47. Kobert K, Salichos L, Rokas A, Stamatakis A. Computing the internode certainty and related measures from partial gene trees. Mol Biol Evol. 2016. https://doi.org/10.1093/molbev/msw040.

48. Shimodaira H. Multiple comparisons of log-likelihoods and combining nonnested models with applications to phylogenetic tree selection. Comm. in Statist., Part A - Theory Meth. 2001;30:1751-72.

49. Shimodaira H. An approximately unbiased test of phylogenetic tree selection. Syst Biol. 2002;51:492-508.

50. Shimodaira $\mathrm{H}$. Approximately unbiased tests of regions using multistepmultiscale bootstrap resampling. Ann Stat. 2004;32:2616-41.

51. Shimodaira H, Hasegawa M. CONSEL: for assessing the confidence of phylogenetic tree selection. Bioinformatics. 2001;17:1246-7.

52. Patterson C, Rosen DE. Review of ichthyodectiform and other Mesozoic teleost fishes and the theory and practice of classifying fossils. Bull Am Mus Nat. 1977;158:83-172.

53. Grande L. A revision of the fossil genus Diplomystus, with comments on the interrelationships of clupeomorphs fishes. Amer Mus Novitates. 1982;2728:1-34.

54. Chang MM, Maisey JG. Redescription oft Ellimma branneri and Diplomystus shengliensis, and relationships of some basal clupeomorphs. Am Mus Novit. 2003;3404:1-35

55. Hughes LC, Ortí G, Huang Y, Sun Y, Baldwin CC, Thompson AW, Arcila D, Betancur-R R, Li C, Becker L, Bellora N, Zhao X, Li X, Wang M, Fang C, Xie B, Zhou Z, Huang H, Chen S, Venkatesh B, Shi Q. Comprehensive phylogeny of ray-finned fishes (Actinopterygii) based on transcriptomic and genomic data. Proc Natl Acad Sci. 2018. https://doi.org/10.1073/pnas.1719358115.

56. Greenwood PH. The osteology and relationships of the Denticipitidae, a family of clupeomorph fishes. Bull Brit Mus Nat Hist Zool. 1968;16:213-73.

57. Ortí G, Meyer A. Molecular evolution of ependymin and the phylogenetic resolution of early divergences among euteleost fishes. Mol Biol Evol. 1996; 13:556-73.

58. Ortí G, Meyer A. The radiation of characiform fishes and the limits of resolution of mitochondrial ribosomal DNA sequences. Syst Biol. 1997:46:75-100.

59. Nakatani M, Miya M, Mabuchi K, Saitoh K, Nishida M. Evolutionary history of Otophysi (Teleostei), a major clade of the modern freshwater fishes: Pangaean origin and Mesozoic radiation. BMC Evol Biol. 2011;11:e177. 
60. Chen WJ, Lavoué S, Mayden RL. Evolutionary origin and early biogeography of otophysan fishes (Ostariophysi: Teleostei). Evolution. 2013;67:2218-39.

61. Campbell MA, Alfaro ME, Belasco M, Lopez JA. Early-branching euteleost relationships: areas of congruence between concatenation and coalescent model inferences. PeerJ. 2017. https://doi.org/10.7717/peerj.3548.

62. Burridge CP, McDowall RM, Craw D, Wilson MVH, Waters JM. Marine dispersal as a pre-requisite for Gondwanan vicariance among elements of the galaxiid fish fauna. J Biogeogr. https://doi.org/10.1111/j.1365-2699.2011.02600.x.

63. Rosen DE. Interrelationships of higher euteleostean fishes. In: Greenwood PH, Miles RS, Patterson C, editors. Interrelationships of fishes. London: Academic Press; 1973. p. 397-513.

64. Johnson GD. Monophyly of the euteleostean clades: Neoteleostei. Eurypterygii and Ctenosquamata Copeia. 1992;1:8-25.

65. Springer VG, Johnson DG. Study of the dorsal gill-arch musculature of teleostome fishes, with special reference to the Actinopterygii. Bull Biol Soc Wash. 2004;11:236-60.

66. Li C, Riethoven J-JM, Ma L. Exon-primed intron-crossing (EPIC) markers for non-model teleost fishes. BMC Evol Biol. 2010. https://doi.org/10.1186/14712148-10-90.

67. Li C, Orti G, Zhang G, Guoquing L. A practical approach to phylogenomics: the phylogeny of ray-finned fish (Actinopterygii) as a case study. BMC Evol Biol. 2007. https://doi.org/10.1186/1471-2148-7-44.

68. Li C, Hofreiter M, Straube N, Corrigan S, Naylor GJP. Capturing proteincoding genes across highly divergent species. BioTechniques. 2013;54(6): 321-6.

69. Fisher S, Barry A, Abreu J, Minie B, Nolan J, Delorey TM, Young G, Fennell TJ, Allen A, Ambrogio L, Berlin AM, Blumenstiel B, Cibulskis K, Friedrich D, Johnson R, Juhn F, Reilly B, Shammas R, Stalker J, Sykes SM, Thompson J, Walsh J, Zimmer A, Zwirko Z, Gabriel S, Robert N, Nusbaum C. A scalable, fully automated process for construction of sequence-ready human exome targeted capture libraries. Genome Biol. 2011. https:/doi.org/10.1186/gb-2011-12-1-r1.

70. Springer MS, Signore AV, Paijmans JL, Vélez-Juarbe J, Domning DP, Bauer CE, He K, Crerar L, Campos PF, Murphy WJ, Meredith RW, Gatesy J, Willerslev E, MacPhee RD, Hofreiter M, Campbell KL. Interordinal gene capture, the phylogenetic position of Steller's sea cow based on molecular and morphological data, and the macroevolutionary history of Sirenia. Mol Phylogenetics Evol. 2015;91:178-93.

71. Martin M. Cutadapt removes adapter sequences from high-throughput sequencing reads. EMBnet J. 2011. https://doi.org/10.14806/ej.17.1.200.

72. Krueger F. (2016) Trimgalore https://www.bioinformatics.babraham.ac.uk/ projects/trim_galore/. Accessed 24 April 2018

73. Haas BJ, Papanicolaou A, Yassour M, Grabherr M, Blood PD, Bowden J, Couger MB, Eccles D, Li B, Lieber M, MacManes MD, Ott M, Orvis J, Pochet N, Strozzi F, Weeks N, Westerman R, William T, Dewey CN, Henschel R, LeDuc RD, Friedman N, Regev A. De novo transcript sequence reconstruction from RNA-Seq: reference generation and analysis with trinity. Nature Protoc. 2013. https://doi.org/10.1038/nprot.2013.084

74. Katoh K, Misawa K, Kuma KI, Miyata T. MAFFT: a novel method for rapid multiple sequence alignment based on fast Fourier transform. Nuc Ac Res. 2002. https://doi.org/10.1093/nar/gkf436. PMC 135756.

75. Katoh K, Kuma Kl, Toh H, Miyata T. MAFFT version 5: improvement in accuracy of multiple sequence alignment. Nuc Ac Res. 2005. https://doi.org/ 10.1093/nar/gki198. PMC 548345

76. Ballenghien M, Faivre N, Galtier N. Patterns of cross-contamination in a multispecies population genomic project: detection, quantification, impact, and solutions. BMC Biol. 2017. 10.11 86/s12915-017-0366-6.

77. Pattengale ND, Alipour M, Bininda-Edmonds ORP, Moret BME, Stamatakis A. How many bootstrap replicates are necessary? J Comput Biol. 2010. https://doi.org/10.1089/cmb.2009.0179.

78. Lartillot N, Philippe H. A Bayesian mixture model for across site heterogeneities in the amino-acid replacement process. Mol Biol Evol. 2004;21(6):1095-109.

79. Lartillot N, Brinkmann H, Philippe H. Suppression of long-branch attraction artefacts in the animal phylogeny using a site-heterogeneous model. BMC Evol Biol. 2007. https://doi.org/10.1186/1471-2148-7-S1-S4.

80. Miller MA, Pfeiffer W, Schwartz T. Creating the CIPRES Science Gateway for inference of large phylogenetic trees. In: Proceedings of the Gateway Computing Environments Workshop. San Diego; 2010. p. 1-8.

81. Dingerkus $G$, Uhler LD. Enzyme clearing of Alcian blue stained whole smal vertebrates for demonstration of cartilage. Stain Technol. 1977;52:229-32.

82. Taylor WR, CVD VD. Revised procedures for staining and clearing small fishes and other vertebrates for bone and cartilage study. Cybium. 1985;9:107-19.

Ready to submit your research? Choose BMC and benefit from:

- fast, convenient online submission

- thorough peer review by experienced researchers in your field

- rapid publication on acceptance

- support for research data, including large and complex data types

- gold Open Access which fosters wider collaboration and increased citations

- maximum visibility for your research: over $100 \mathrm{M}$ website views per year

At BMC, research is always in progress.

Learn more biomedcentral.com/submissions 